\title{
Clinical Outcomes of COVID-19 Patients with Type 2 Diabetes: A Population-Based Study in Korea
}

\author{
Ji Hong You ${ }^{1, *}$, Sang Ah Lee ${ }^{2,3, *}$, Sung-Youn Chun ${ }^{2,3}$, Sun Ok Song ${ }^{3,4}$, Byung-Wan Lee ${ }^{5}$, Dae Jung Kim ${ }^{6}$, \\ Edward J. Boyko ${ }^{7,8}$
}

${ }^{1}$ Division of Endocrinology and Metabolism, Department of Internal Medicine, Keimyung University Dongsan Hospital, Keimyung University School of Medicine, Daegu; ${ }^{2}$ Research and Analysis Team, National Health Insurance Service Ilsan Hospital; ${ }^{3}$ Research Institute of National Health Insurance Service Ilsan Hospital; ${ }^{4}$ Division of Endocrinology and Metabolism, Department of Internal Medicine, National Health Insurance Service Ilsan Hospital, Goyang; ${ }^{5}$ Division of Endocrinology and Metabolism, Department of Internal Medicine, Severance Hospital, Yonsei University College of Medicine, Seoul; ${ }^{6}$ Department of Endocrinology and Metabolism, Ajou University School of Medicine, Suwon, Korea; ${ }^{7}$ Seattle Epidemiologic Research and Information Center, VA Puget Sound Health Care System; ${ }^{8}$ Department of Medicine, University of Washington, Seattle, WA, USA

Background: The aim of this study was to evaluate clinical outcomes in coronavirus disease 2019 (COVID-19) positive patients with type 2 diabetes compared to those without diabetes in Korea.

Methods: We extracted claims data for patients diagnosed with COVID-19 from the National Health Insurance Service database in Korea from January 20, 2020 to March 31, 2020. We followed up this cohort until death from COVID-19 or discharge from hospital. Results: A total of 5,473 patients diagnosed with COVID-19 were analyzed, including 495 with type 2 diabetes and 4,978 without diabetes. Patients with type 2 diabetes were more likely to be treated in the intensive care unit (ICU) $(P<0.0001)$. The incidence of inhospital mortality was higher in patients with type 2 diabetes $(P<0.0001)$. After adjustment for age, sex, insurance status, and comorbidities, odds of ICU admission (adjusted odds ratio [OR], 1.59; 95\% confidence interval [CI], 1.02 to 2.49; $P=0.0416$ ) and in-hospital mortality (adjusted OR, 1.90; $95 \% \mathrm{CI}, 1.13$ to $3.21 ; P=0.0161$ ) among patients with COVID-19 infection were significantly higher in those with type 2 diabetes. However, there was no significant difference between patients with and without type 2 diabetes in ventilator, oxygen therapy, antibiotics, antiviral drugs, antipyretics, and the incidence of pneumonia after adjustment.

Conclusion: COVID-19 positive patients with type 2 diabetes had poorer clinical outcomes with higher risk of ICU admission and in-hospital mortality than those without diabetes. Therefore, medical providers need to consider this more serious clinical course when planning and delivering care to type 2 diabetes patients with COVID-19 infection.

Keywords: COVID-19; Diabetes mellitus, type 2; Incidence; Mortality; Epidemiology

Received: 24 July 2020, Revised: 13 October 2020, Accepted: 3 November 2020 Corresponding authors: Sun Ok Song

Division of Endocrinology and Metabolism, Department of Internal Medicine, National Health Insurance Service Ilsan Hospital, 100 Ilsan-ro, Ilsandong-gu, Goyang 10444, Korea

Tel: +82-31-900-3470, Fax: +82-31-900-0519, E-mail: songsun7777@gmail.com

Dae Jung Kim

Department of Endocrinology and Metabolism, Ajou University School of Medicine, 164 World Cup-ro, Yeongtong-gu, Suwon 16499, Korea

Tel: +82-31-219-5128, Fax: +82-31-219-4497, E-mail: djkim@ajou.ac.kr

\section{Copyright $@ 2020$ Korean Endocrine Society}

This is an Open Access article distributed under the terms of the Creative Commons Attribution Non-Commercial License (https://creativecommons.org/ licenses/by-nc/4.0/) which permits unrestricted non-commercial use, distribution, and reproduction in any medium, provided the original work is properly cited.

*These authors contributed equally to this work. 


\section{INTRODUCTION}

There is currently a global struggle to contain an outbreak of coronavirus disease 2019 (COVID-19), caused by severe acute respiratory syndrome coronavirus-2 (SARS-CoV-2). In March 2020, the World Health Organization declared COVID-19 a pandemic. As of July 22, 2020, more than 14.8 million persons have been diagnosed with COVID-19 in the world, with more than 610,000 deaths. In Korea, the first confirmed case of COVID-19 occurred on January 20, 2020. Korea had globally the second largest number of patients with COVID-19 in the early days of the outbreak until March 2020.

Presence of co-morbid conditions have been reported more frequently in patients who died with COVID-19 infection. In Korea, $96.8 \%$ of COVID-19 positive patients who died had underlying diseases and $36.5 \%$ had diabetes [1]. According to Yang et al. [2], 22\% of persons who died of COVID-19 in Wuhan Jinyintan Hospital had diabetes. In a multi-center observational study of 1,082 COVID-19 positive patients in Daegu, Korea, those with diabetes also exhibited higher mortality [3].

Type 2 diabetes is one of the most prevalent chronic diseases worldwide. In 2018, its prevalence in the United States was over $10 \%$ and it exceeded $25 \%$ in the elderly [4]. In Europe, the prevalence of type 2 diabetes is close to $10 \%$ [5]. In 2008, the prevalence of type 2 diabetes was $14.4 \%$ in Korea, with $29.8 \%$ of the elderly population affected, and its prevalence has continued to increase [6].

Studies about the association between COVID-19 and type 2 diabetes has been reported from around the world. However, there are only a few large-scale national studies of the clinical course of COVID-19 positive patients with type 2 diabetes in Asia, including Korea. Therefore, the purpose of this study was to investigate clinical outcomes in COVID-19 positive patients with type 2 diabetes compared to those without diabetes in a national data in Korea.

\section{METHODS}

\section{Data source}

In this study, we used National Health Insurance (NHI) claims data from the Health Insurance Review \& Assessment Service (HIRA) that is a government-affiliated agency which supervises all medical services in Korea under the Ministry of Health and Welfare [7]. This database is maintained by the National Health Insurance System (NHIS). The NHIS is the only public medical insurance system in Korea and represents the entire Korean population, because of the compulsory social insurance system. All clinics and hospitals in Korea submit inpatient and outpatient data, including information on the diagnosis and medical costs, to the NHIS to claim payments for patient care [7]. People who are not included in NHIS due to the lowest income bracket are covered by tax-funded programs, including Medicaid.

The database consists of the following four categories: general information on specifications; consultation statements; diagnosis statements based on the International Classification of Diseases, 10th revision (ICD-10) guidelines; and detailed information about prescriptions [7]. The NHIS contains information on patient demographics, medical use/transactions, deductions and claims, and insurers' payment coverage [8]. We extracted information for each individual including age, gender, diagnosis, prescribed drugs, and pharmacy expenditure, using an unidentifiable code. The protocol was reviewed and approved by the Institutional Review Board of the National Health Insurance Service Ilsan Hospital (NHIMC 2020-03-084). The requirement for informed consent was waived by the board.

\section{Operational diagnosis of type 2 diabetes and anti-diabetic medications}

Retrospective data for patients with type 2 diabetes were extracted from January 2019 to December 2019. Individuals were considered to have type 2 diabetes if anti-diabetic drugs were prescribed with the presence of ICD-10 codes E11, E12, E13, or E14, as either a principal diagnosis or the 1st to 4th additional diagnosis at least once a year [8]. Antidiabetic drugs dispensed by the pharmacy during the study period and identified in claims records consisted of nine classes (i.e., insulin; biguanide; sulfonylurea; thiazolidinedione; dipeptidyl peptidase-4 inhibitor [DPP-4i]; sodium-glucose cotransporter 2 inhibitor; meglitinide, alpha-glucosidase inhibitor; and glucagon-like peptide-1 agonists) [9]. Patients with type 1 diabetes, defined by three or more insulin prescriptions with the presence of an E10 ICD-10 code, were excluded [10].

\section{Detection of COVID-19 cases and deaths}

We identified COVID-19 cases based on information from the Korea Center for Disease Control \& Prevention. COVID-19 diagnoses were made between January 20, 2020 and March 31, 2020. After 10 cases were excluded due to missing date, 5,473 patietns diagnosed with COVID-19 were analyzed during study period. We followed up the cases until their death from COVID-19 or their discharge from hospital. 


\section{Covariates and clinical care outcomes}

Covariates were selected based on the available variables which HIRA provided. Age groups were categorized using 10-year intervals. Insurance types were analyzed in terms of NHI and medical aid, which reflect economic status, because the insurers' payments are subdivided by the patient's economic status as described above. Comorbidities were categorized into 14 classes and were determined based on ICD-10 codes [11]. We evaluated treatment variables including intensive care unit (ICU) admission, ventilator, oxygen therapy, antibiotics, antiviral drugs, and antipyretics. To evaluate clinical care outcomes, the incidence of pneumonia and in-hospital mortality were analyzed.

\section{Statistical analysis}

We used chi-square test to analyze numerical and frequency data. Odds ratios (ORs) and 95\% confidence intervals (CIs) between the two groups of interest were calculated using multiple logistic regression, with adjustment for age, sex, insurance status, and comorbidities. Subgroup analysis was conducted to investigate the association between diabetes and in-hospital mortality by age groups. A $P<0.05$ was considered to indicate a statistically significant result. All analyses were performed using SAS statistical software version 9.4 (SAS Institute, Cary, NC, USA).

\section{RESULTS}

\section{Baseline characteristics of the study population}

This study consisted of 5,473 patients diagnosed with COVID-19, including 495 patients with type 2 diabetes and 4,978 patients without type 2 diabetes. Their demographic data, including age, sex, insurance type, and antidiabetic drug usage, are presented in Table 1. Patients with type 2 diabetes tended to be older $(34.5 \%$ vs. $8.2 \%$ aged $\geq 70$ years $)$ and male $(56.4 \%$ vs. $43.4 \%, P<0.0001)$. The percentage of persons accessing medical aid was greater in the type 2 diabetes group. Of the patients with type 2 diabetes, $18.6 \%$ were using insulin, while metformin and DPP-4i were the most prevalent oral hypoglycemic agents (OHAs) (49.1\% and 34.9\%, respectively; $P<0.0001)$.

\section{Comorbidities, treatments, and outcomes of COVID-19 positive patients with or without type 2 diabetes}

Hypertension (63.8\%), pulmonary disease (34.6\%), renal disease $(21.8 \%)$, cerebrovascular disease $(21.4 \%)$, and myocardial infarction $(17.0 \%)$ were the most common comorbidities in patients with type 2 diabetes (Table 1). In those without type 2 diabetes, pulmonary disease $(28.1 \%)$, hypertension $(15.0 \%)$, and asthma $(9.8 \%)$ were the most common comorbidities. The frequencies of all other comorbidities, except connective tissue disease, were significantly higher in patients with type 2 diabetes $(P<0.0001$, except Asthma $P=0.0336$ and pulmonary disease $P=0.0028)$. Patients with type 2 diabetes were more likely to be treated in the ICU and require oxygen therapy $(P<0.0001)$ and a ventilator $(P=0.0025)$. They were also more likely to be treated with antibiotics, antiviral drugs $(P<0.0001)$, and antipyretics $(P=0.0311)$ than patients without type 2 diabetes. The incidence of pneumonia (13.1\% vs. $7.1 \%$ ) and in-hospital mortality $(5.7 \%$ vs. $1.1 \%)$ were significantly higher in patients with type 2 diabetes $(P<0.0001)$. As a result of classifying COVID-19 positive patients with type 2 diabetes according to antidiabetic drugs (Supplemental Table S1), there was no significant difference between patients with $\mathrm{OHAs}$ and insulin $\pm \mathrm{OHAs}$ in variables including outcomes, except for hypertension, myocardial infarction, renal diseases, antiviral, and antipyretics.

\section{Multivariate analysis of treatments and outcomes of COVID-19 positive patients with type 2 diabetes}

After adjusting for age, sex, insurance type, and comorbidities, there was significantly higher ICU admission frequency in $\mathrm{CO}$ VID-19 positive patients with type 2 diabetes (adjusted OR, 1.59 ; $95 \%$ CI, 1.01 to $2.49 ; P=0.0416$ ) (Table 2 ). The in-hospital mortality rate was also higher for those with type 2 diabetes (adjusted OR, 1.90; 95\% CI, 1.13 to $3.21 ; P=0.0161$ ). However, there were no significant differences in other outcomes between those with and without type 2 diabetes. Additionally, we analyzed whether antidiabetic drugs affected treatment and outcome variables (Supplemental Table S2). After adjustment for age, sex, insurance type, and comorbidities, antidiabetic drugs including metformin and DPP-4i were not associated with treatment and outcome variables in COVID-19 patients with type 2 diabetes.

Table 3 shows the frequency of in-hospital mortality by age in COVID-19 positive patients with and without type 2 diabetes. In the age range of 60 to 69 years, the in-hospital mortality rate was significantly higher in patients with type 2 diabetes compared to patients without diabetes $(P=0.0074)$. After adjusting for sex, insurance status, and comorbidities, patients with type 2 diabetes had a significantly higher in-hospital mortality rate (adjusted OR, $7.83 ; 95 \% \mathrm{CI}, 1.76$ to $34.77 ; P=0.0068$ ) in the age range of 60 to 69 years (Supplemental Table S3). Those in the age range of $\geq 70$ years also showed a higher OR of in-hospital mortality, but this difference was not statistically significant. Adjusted ORs for other treatment and outcome variables by age 
Table 1. The Demographics of the Study Population

\begin{tabular}{|c|c|c|c|c|}
\hline \multirow{2}{*}{ Variable } & \multicolumn{3}{|c|}{ Number (\%) } & \multirow{2}{*}{$P$ value } \\
\hline & Total & No diabetes & Type 2 diabetes & \\
\hline Total & $5,473(100.0)$ & $4,978(91.0)$ & $495(9.0)$ & \\
\hline Sex & & & & $<0.0001$ \\
\hline Male & 2,439 (44.6) & $2,160(43.4)$ & $279(56.4)$ & \\
\hline Female & $3,034(55.4)$ & $2,818(56.6)$ & $216(43.6)$ & \\
\hline Age group, yr & & & & $<0.0001$ \\
\hline$<20$ & $421(7.7)$ & $419(8.4)$ & $2(0.4)$ & \\
\hline $20-29$ & $1,269(23.2)$ & $1,261(25.3)$ & $8(1.6)$ & \\
\hline $30-39$ & 970 (17.7) & $956(19.2)$ & $14(2.8)$ & \\
\hline $40-49$ & $857(15.7)$ & $792(15.9)$ & $65(13.1)$ & \\
\hline $50-59$ & $807(14.8)$ & $708(14.2)$ & $99(20.0)$ & \\
\hline $60-69$ & $569(10.4)$ & $433(8.7)$ & $136(27.5)$ & \\
\hline$\geq 70$ & $580(10.6)$ & $409(8.2)$ & $171(34.5)$ & \\
\hline Insurance type & & & & $<0.0001$ \\
\hline National Health Insurance & $5,179(94.6)$ & $4,756(95.5)$ & $423(85.5)$ & \\
\hline Medical aids & $294(5.4)$ & $222(4.5)$ & $72(14.5)$ & \\
\hline \multicolumn{5}{|l|}{ Antidiabetic drugs } \\
\hline Insulin & - & - & $92(18.6)$ & \\
\hline OHAs & - & - & & \\
\hline Metformin & - & - & $243(49.1)$ & \\
\hline $\mathrm{SU}$ & - & - & $73(14.7)$ & \\
\hline $\mathrm{TZD}$ & - & - & $13(2.6)$ & \\
\hline DPP-4i & - & - & $173(34.9)$ & \\
\hline SGLT2i & - & - & $15(3.0)$ & \\
\hline Meglitinide & - & - & $5(1.0)$ & \\
\hline AGI & - & - & $2(0.4)$ & \\
\hline GLP-1 & - & - & 0 & \\
\hline \multicolumn{5}{|l|}{ Comorbidities } \\
\hline Hypertension & $1,064(19.4)$ & $748(15.0)$ & $316(63.8)$ & $<0.0001$ \\
\hline Myocardial infarction & $226(4.1)$ & $142(2.9)$ & $84(17.0)$ & $<0.0001$ \\
\hline Heart failure & $111(2.0)$ & $72(1.5)$ & $39(7.9)$ & $<0.0001$ \\
\hline Peripheral artery diseases & $177(3.2)$ & $143(2.9)$ & $34(6.9)$ & $<0.0001$ \\
\hline Cerebrovascular diseases & $332(6.1)$ & $226(4.5)$ & $106(21.4)$ & $<0.0001$ \\
\hline Dementia & $141(2.6)$ & $103(2.1)$ & $38(7.7)$ & $<0.0001$ \\
\hline COPD & $91(1.7)$ & $71(1.4)$ & $20(4.0)$ & $<0.0001$ \\
\hline Asthma & $552(10.1)$ & $488(9.8)$ & $64(12.9)$ & 0.0336 \\
\hline Connective tissue diseases & $99(1.8)$ & $92(1.9)$ & $7(1.4)$ & 0.6071 \\
\hline Pulmonary diseases & $1,568(28.7)$ & $1,397(28.1)$ & $171(34.6)$ & 0.0028 \\
\hline Liver diseases & $44(0.8)$ & $30(0.6)$ & $14(2.8)$ & $<0.0001$ \\
\hline Hemiplegia & $41(0.8)$ & $23(0.5)$ & $18(3.6)$ & $<0.0001$ \\
\hline Renal diseases & $260(4.8)$ & $152(3.1)$ & $108(21.8)$ & $<0.0001$ \\
\hline Cancer & $366(6.7)$ & $298(6.0)$ & $68(13.7)$ & $<0.0001$ \\
\hline
\end{tabular}


Table 1. Continued

\begin{tabular}{|c|c|c|c|c|}
\hline \multirow{2}{*}{ Variable } & \multicolumn{3}{|c|}{ Number (\%) } & \multirow{2}{*}{$P$ value } \\
\hline & Total & No diabetes & Type 2 diabetes & \\
\hline \multicolumn{5}{|l|}{ Treatments } \\
\hline Ventilator & $34(0.6)$ & $25(0.5)$ & $9(1.8)$ & 0.0025 \\
\hline Oxygen therapy & $276(5.0)$ & $208(4.2)$ & $68(13.7)$ & $<0.0001$ \\
\hline Antibiotics & $439(8.0)$ & $360(7.2)$ & $79(16.0)$ & $<0.0001$ \\
\hline Antiviral drugs & $846(15.5)$ & $726(14.6)$ & $120(24.2)$ & $<0.0001$ \\
\hline Antipyretics & $1,190(21.7)$ & $1,063(21.4)$ & $127(25.7)$ & 0.0311 \\
\hline \multicolumn{5}{|l|}{ Outcomes } \\
\hline ICU admission & $154(2.8)$ & $121(2.4)$ & $33(6.7)$ & $<0.0001$ \\
\hline Pneumonia & $417(7.6)$ & $352(7.1)$ & $65(13.1)$ & $<0.0001$ \\
\hline In-hospital mortality & $84(1.5)$ & $56(1.1)$ & $28(5.7)$ & $<0.0001$ \\
\hline
\end{tabular}

OHA, oral hypoglycemic agent; SU, sulfonylurea; TZD, thiazolidinedione; DPP-4i, dipeptidyl peptidase 4 inhibitor; SGLT2i, sodium-glucose cotransporter 2 inhibitor; AGI, alpha-glucosidase inhibitor; GLP-1, glucagon-like peptide-1 agonist; COPD, chronic obstruction pulmonary disease; ICU, intensive care unit.

Table 2. Adjusted ORs of Treatment and Outcome Variables in Coronavirus Disease 2019 Positive Patients with Type 2 Diabetes Compared to Those without Diabetes

\begin{tabular}{|c|c|c|c|c|}
\hline \multirow{2}{*}{ Variable } & \multirow{2}{*}{$\begin{array}{c}\text { No } \\
\text { diabetes }\end{array}$} & \multicolumn{2}{|c|}{ Type 2 diabetes } & \multirow{2}{*}{$P$ value } \\
\hline & & Adjusted OR & $95 \% \mathrm{CI}$ & \\
\hline \multicolumn{5}{|l|}{ Treatments } \\
\hline Ventilator & 1.00 & 1.16 & $0.5-2.65$ & 0.7339 \\
\hline Oxygen therapy & 1.00 & 1.37 & $0.99-1.89$ & 0.0597 \\
\hline Antibiotics & 1.00 & 1.26 & $0.94-1.7$ & 0.1228 \\
\hline Antiviral drugs & 1.00 & 1.15 & $0.89-1.48$ & 0.2753 \\
\hline Antipyretics & 1.00 & 1.11 & $0.87-1.41$ & 0.4139 \\
\hline \multicolumn{5}{|l|}{ Outcomes } \\
\hline ICU admission & 1.00 & 1.59 & $1.02-2.49$ & 0.0416 \\
\hline Pneumonia & 1.00 & 1.16 & $0.85-1.59$ & 0.3467 \\
\hline In-hospital mortality & 1.00 & 1.90 & $1.13-3.21$ & 0.0161 \\
\hline
\end{tabular}

The comparisons were made using subjects without diabetes as the reference group. The ORs were adjusted for age, sex, insurance type, comorbidities (hypertension, myocardial infarction, heart failure, peripheral disease, cerebrovascular disease, dementia, chronic obstruction pulmonary disease, connective tissue disease, pulmonary disease, liver disease, hemiplegia, renal diseases, and cancer).

$\mathrm{OR}$, odds ratio; CI, confidence interval; ICU, intensive care unit.

group showed no statistically significant differences (data not shown).

\section{DISCUSSION}

This nationwide study based on claims data investigated the as-
Table 3. Frequency of In-Hospital Mortality by Age in Coronavirus Disease 2019 Positive Patients with or without Type 2 Diabetes

\begin{tabular}{|c|c|c|c|c|c|}
\hline \multirow{2}{*}{$\begin{array}{l}\text { In-hospital } \\
\text { mortality }\end{array}$} & \multicolumn{2}{|c|}{$\begin{array}{c}\text { No diabetes } \\
(n=4,978)\end{array}$} & \multicolumn{2}{|c|}{$\begin{array}{c}\text { Type } 2 \text { diabetes } \\
(n=495)\end{array}$} & \multirow[t]{2}{*}{$P$ value } \\
\hline & No. & $\begin{array}{l}\text { Mortality } \\
\text { rate, } / 1,000 \\
\text { cases }\end{array}$ & No. & $\begin{array}{c}\text { Mortality } \\
\text { rate, } / 1,000 \\
\text { cases }\end{array}$ & \\
\hline \multicolumn{6}{|c|}{ Age group, yr } \\
\hline$<20$ & 0 & 0 & 0 & 0 & - \\
\hline $20-29$ & 1 & 0.788 & 0 & 0 & 1.0000 \\
\hline $30-39$ & 0 & 0 & 0 & 0 & - \\
\hline $40-49$ & 2 & 2.525 & 0 & 0 & 1.0000 \\
\hline $50-59$ & 12 & 16.949 & 1 & 10.101 & 1.0000 \\
\hline $60-69$ & 3 & 6.926 & 6 & 44.118 & 0.0074 \\
\hline$\geq 70$ & 38 & 92.910 & 21 & 122.807 & 0.2930 \\
\hline Total & 56 & & 28 & & \\
\hline
\end{tabular}

sociation between COVID-19 and type 2 diabetes in Korea. ICU admission and in-hospital mortality rates were significantly higher in COVID-19 positive patients with type 2 diabetes. Our results confirmed that type 2 diabetes was associated with an increased risk of severity in Korean COVID-19 positive patients.

Type 2 diabetes is known to be a risk factor for morbidity and mortality in patients with infections, including pneumonia [12]. In a population-based cohort study, Kornum et al. [13] reported that type 2 diabetes and high glucose levels on admission were associated with increased pneumonia-related mortality rates. 
Another population-based case-control study showed that type 2 diabetes and poor glycemic control were risk factors for pneumonia-related hospitalization [14]. Type 2 diabetes has also been an important risk factor in previously reported viral infections. During the 2009 influenza A (H1N1) pandemic, patients with type 2 diabetes had a three-fold increased risk of hospitalization and a four-fold increased risk of ICU admission [15]. In patients with SARS-CoV, type 2 diabetes was a risk factor and an independent predictor of mortality and morbidity [16]. Patients with type 2 diabetes also had a 2.8-fold higher risk of mortality after infection with the Middle East respiratory syndrome-related coronavirus (MERS-CoV) [17]. Our findings of high risk of both ICU care and in-hospital mortality are consistent with the past findings from research on other coronavirus outbreaks.

Type 2 diabetes causes the dysregulation of immune mechanisms. A preclinical study showed that the inflammatory response of the lungs was slower in mice with diabetes than in normal mice, and the reaction time in response to MERS-CoV infection was longer [18]. Mice with diabetes were shown to have relatively lower levels of inflammatory cytokines and fewer leukocytes. Other clinical studies also demonstrated that components of the host defense system were impaired in patients with type 2 diabetes, especially the innate immune system and leukocytes $[19,20]$. Hyperglycemia itself has harmful effects by impairing components of the immune system, such as the chemotaxis and phagocytosis of leukocytes [21,22]. Stress hyperglycemia increases cytokine production and mortality in septic conditions [23]. In addition, antioxidant systems involved in bactericidal activity can be impaired in patients with type 2 diabetes [24]. It is estimated that these host response impairments in diabetes would lead to high levels of morbidity and mortality with serious infections such as COVID-19.

Previous studies on COVID-19 support our findings that ICU admission and in-hospital mortality rates were higher in patients with type 2 diabetes. A study of 174 Chinese COVID-19 positive patients reported that patients with diabetes who had no other comorbidities had higher mortality rates $(16.7 \%$ vs. $0 \%$, $P=0.03$ ) [25]. The same study showed that there was a release of tissue injury-related enzymes, uncontrolled inflammation responses, and a hypercoagulable state in patients with diabetes. Another study demonstrated, using a univariate analysis, that the OR of in-hospital death was higher in patients with diabetes (OR, 2.85; 95\% CI, 1.35 to $6.05 ; P=0.0062$ ) [26]. Guan et al. [27] also reported that more patients with diabetes died $(10.0 \%$ vs. $2.5 \%$ ), and were admitted to the ICU (14.6\% vs. $5.5 \%)$ com- pared with those without diabetes in a nationwide analysis in China that included about one-third as many patients as included in our analyses. The hazard ratio of diabetes was 1.586 in the same study (95\% CI, 1.03 to $2.45 ; P=0.037$ ).

This study did not show associations between antidiabetic drugs and clinical outcomes in COVID-19 positive patients with type 2 diabetes. Previous studies reported that metformin treatment was associated with reduced mortality in COVID-19 patients with type 2 diabetes [28,29]. Metformin is known to have the anti-inflammatory properties that may influence the clinical outcomes in COVID-19 infection. Other previous studies reported that coronaviruses, SARS-CoV and MERS-CoV, entered the cells by binding to DPP-4 enzyme [30,31]. It has been speculated that DPP-4i may be associated with COVID-19 infection. Further research is necessary to clarify the relationship between antidiabetic drugs and COVID-19.

The present study had some limitations that should be addressed in further investigations. Firstly, the data analyzed in our study were based on NHI claims. Clinical information, such as the state of blood glucose control in patients with type 2 diabetes, was not available. In addition, potential confounding variables such as smoking and obesity status were also not available. Secondly, this study was not able to consider the duration of type 2 diabetes and treatment, because the data analyzed were from January 2019. Thirdly, we were unable to assess the association between COVID-19 and type 1 diabetes, since there were no COVID-19 positive patients with type $1 \mathrm{di}$ abetes in our data set. Additionally, date of death was not provided by HIRA due to the possibility of tracking patients. Therefore, survival time could not be calculated.

The strength of our study is that it is a nationwide analysis of COVID-19 positive patients in Korea. This study is also the first to evaluate COVID-19 outcomes in Korean people with type 2 diabetes, compared to those without diabetes. Our population included a considerable number of younger people without other comorbidities due to an outbreak of COVID-19 in a specific Korean religious group having many young members especially between ages 20 to 29 years. Only one death occurred in patients under age 40 years, and no deaths in these younger persons with diabetes, although the number with this condition was small.

In conclusion, COVID-19 positive patients with type 2 diabetes showed poorer clinical outcomes such as higher risk of ICU admission and in-hospital mortality than those without diabetes. Therefore, medical providers need to consider this more serious clinical course when planning and delivering care to type 2 dia- 
betes patients with COVID-19 infection. Further studies are needed to evaluate the mechanism whereby type 2 diabetes negatively impacts outcomes in COVID-19.

\section{CONFLICTS OF INTEREST}

No potential conflict of interest relevant to this article was reported.

\section{ACKNOWLEDGMENTS}

The authors appreciate healthcare professionals dedicated to treating COVID-19 patients in Korea, the Ministry of Health and Welfare, and the Health Insurance Review \& Assessment Service of Korea for sharing invaluable national health insurance claims data in a prompt manner. We would like to thank Editage (www.editage.co.kr) for English language editing.

\section{AUTHOR CONTRIBUTIONS}

Conception or design: J.H.Y., S.A.L., S.O.S. Acquisition, analysis, or interpretation of data: J.H.Y., S.A.L., S.Y.C., S.O.S., B.W.L., D.J.K., E.J.B. Drafting the work or revising: J.H.Y., S.A.L., S.O.S. Final approval of the manuscript: J.H.Y., S.A.L., S.O.S., B.W.L., D.J.K., E.J.B.

\section{ORCID}

Ji Hong You https://orcid.org/0000-0003-1544-7094

Sang Ah Lee https://orcid.org/0000-0001-5415-0141

Sun Ok Song https://orcid.org/0000-0003-4829-3407

Dae Jung Kim https://orcid.org/0000-0003-1025-2044

\section{REFERENCES}

1. COVID-19 National Emergency Response Center, Epidemiology and Case Management Team, Korea Centers for Disease Control and Prevention. Coronavirus disease-19: the first 7,755 cases in the Republic of Korea. Osong Public Health Res Perspect 2020;11:85-90.

2. Yang X, Yu Y, Xu J, Shu H, Xia J, Liu H, et al. Clinical course and outcomes of critically ill patients with SARSCoV-2 pneumonia in Wuhan, China: a single-centered, retrospective, observational study. Lancet Respir Med 2020;8: 475-81.

3. Kim MK, Jeon JH, Kim SW, Moon JS, Cho NH, Han E, et al. The clinical characteristics and outcomes of patients with moderate-to-severe coronavirus disease 2019 infection and diabetes in Daegu, South Korea. Diabetes Metab J 2020;44: 602-13.

4. Centers for Disease Control and Prevention. National diabetes statistics report 2020. Atlanta: Centers for Disease Control and Prevention, US Department of Health and Human Services; 2020.

5. Tamayo T, Rosenbauer J, Wild SH, Spijkerman AM, Baan C, Forouhi NG, et al. Diabetes in Europe: an update. Diabetes Res Clin Pract 2014;103:206-17.

6. Kim BY, Won JC, Lee JH, Kim HS, Park JH, Ha KH, et al. Diabetes fact sheets in Korea, 2018: an appraisal of current status. Diabetes Metab J 2019;43:487-94.

7. Song SO, Jung CH, Song YD, Park CY, Kwon HS, Cha BS, et al. Background and data configuration process of a nationwide population-based study using the Korean National Health Insurance system. Diabetes Metab J 2014;38:395403.

8. Lee YH, Han K, Ko SH, Ko KS, Lee KU; Taskforce Team of Diabetes Fact Sheet of the Korean Diabetes Association. Data analytic process of a nationwide population-based study using national health information database established by National Health Insurance Service. Diabetes Metab J 2016;40:79-82.

9. Ko SH, Kim DJ, Park JH, Park CY, Jung CH, Kwon HS, et al. Trends of antidiabetic drug use in adult type 2 diabetes in Korea in 2002-2013: nationwide population-based cohort study. Medicine (Baltimore) 2016;95:e4018.

10. Song SO, Song YD, Nam JY, Park KH, Yoon JH, Son KM, et al. Epidemiology of type 1 diabetes mellitus in Korea through an investigation of the national registration project of type 1 diabetes for the reimbursement of glucometer strips with additional analyses using claims data. Diabetes Metab J 2016;40:35-45.

11. Sundararajan V, Henderson T, Perry C, Muggivan A, Quan H, Ghali WA. New ICD-10 version of the Charlson comorbidity index predicted in-hospital mortality. J Clin Epidemiol 2004;57:1288-94.

12. Rao Kondapally Seshasai S, Kaptoge S, Thompson A, Di Angelantonio E, Gao P, Sarwar N, et al. Diabetes mellitus, fasting glucose, and risk of cause-specific death. N Engl J Med 2011;364:829-41.

13. Kornum JB, Thomsen RW, Riis A, Lervang HH, Schonheyder HC, Sorensen HT. Type 2 diabetes and pneumonia outcomes: a population-based cohort study. Diabetes Care 
2007;30:2251-7.

14. Kornum JB, Thomsen RW, Riis A, Lervang HH, Schonheyder HC, Sorensen HT. Diabetes, glycemic control, and risk of hospitalization with pneumonia: a population-based casecontrol study. Diabetes Care 2008;31:1541-5.

15. Allard R, Leclerc P, Tremblay C, Tannenbaum TN. Diabetes and the severity of pandemic influenza A (H1N1) infection. Diabetes Care 2010;33:1491-3.

16. Chan JW, Ng CK, Chan YH, Mok TY, Lee S, Chu SY, et al. Short term outcome and risk factors for adverse clinical outcomes in adults with severe acute respiratory syndrome (SARS). Thorax 2003;58:686-9.

17. Banik GR, Alqahtani AS, Booy R, Rashid H. Risk factors for severity and mortality in patients with MERS-CoV: analysis of publicly available data from Saudi Arabia. Virol Sin 2016;31:81-4.

18. Kulcsar KA, Coleman CM, Beck SE, Frieman MB. Comorbid diabetes results in immune dysregulation and enhanced disease severity following MERS-CoV infection. JCI Insight 2019;4:e131774.

19. Nolan CM, Beaty HN, Bagdade JD. Further characterization of the impaired bactericidal function of granulocytes in patients with poorly controlled diabetes. Diabetes 1978;27: 889-94.

20. Bagdade JD, Root RK, Bulger RJ. Impaired leukocyte function in patients with poorly controlled diabetes. Diabetes 1974;23:9-15.

21. Delamaire M, Maugendre D, Moreno M, Le Goff MC, Allannic H, Genetet B. Impaired leucocyte functions in diabetic patients. Diabet Med 1997;14:29-34.

22. Marhoffer W, Stein M, Maeser E, Federlin K. Impairment of polymorphonuclear leukocyte function and metabolic control of diabetes. Diabetes Care 1992;15:256-60.

23. Leonidou L, Mouzaki A, Michalaki M, DeLastic AL, Kyri- azopoulou V, Bassaris HP, et al. Cytokine production and hospital mortality in patients with sepsis-induced stress hyperglycemia. J Infect 2007;55:340-6.

24. Muchova J, Liptakova A, Orszaghova Z, Garaiova I, Tison P, Carsky J, et al. Antioxidant systems in polymorphonuclear leucocytes of type 2 diabetes mellitus. Diabet Med 1999;16: 74-8.

25. Guo W, Li M, Dong Y, Zhou H, Zhang Z, Tian C, et al. Diabetes is a risk factor for the progression and prognosis of COVID-19. Diabetes Metab Res Rev 2020;36:e3319.

26. Zhou F, Yu T, Du R, Fan G, Liu Y, Liu Z, et al. Clinical course and risk factors for mortality of adult inpatients with COVID-19 in Wuhan, China: a retrospective cohort study. Lancet 2020;395:1054-62.

27. Guan WJ, Liang WH, Zhao Y, Liang HR, Chen ZS, Li YM, et al. Comorbidity and its impact on 1590 patients with COVID-19 in China: a nationwide analysis. Eur Respir J 2020; 55:2000547.

28. Cariou B, Hadjadj S, Wargny M, Pichelin M, Al-Salameh A, Allix I, et al. Phenotypic characteristics and prognosis of inpatients with COVID-19 and diabetes: the CORONADO study. Diabetologia 2020;63:1500-15.

29. Luo P, Qiu L, Liu Y, Liu XL, Zheng JL, Xue HY, et al. Metformin treatment was associated with decreased mortality in COVID-19 patients with diabetes in a retrospective analysis. Am J Trop Med Hyg 2020;103:69-72.

30. Yuan Y, Qi J, Peng R, Li C, Lu G, Yan J, et al. Molecular basis of binding between Middle East respiratory syndrome coronavirus and CD26 from seven bat species. J Virol 2020; 94:e01387-19.

31. Raj VS, Mou H, Smits SL, Dekkers DH, Muller MA, Dijkman R, et al. Dipeptidyl peptidase 4 is a functional receptor for the emerging human coronavirus-EMC. Nature 2013; 495:251-4. 